\title{
To Process or to Decay: A Mechanistic View of the Nuclear RNA Exosome
}

\author{
Mahesh Lingaraju, ${ }^{1}$ Jan M. Schuller,${ }^{1}$ Sebastian Falk, ${ }^{2}$ Piotr Gerlach, ${ }^{1}$ \\ Fabien Bonneau, ${ }^{1}$ Jérôme Basquin, ${ }^{1}$ Christian Benda, ${ }^{1}$ and Elena Conti ${ }^{1}$ \\ ${ }^{1}$ Max-Planck-Institute of Biochemistry, Department of Structural Cell Biology, D-82152 \\ Martinsried/Munich, Germany \\ ${ }^{2}$ Max Perutz Labs, Department of Structural and Computational Biology, University of Vienna, \\ 1030, Vienna, Austria \\ Correspondence: conti@biochem.mpg.de
}

\begin{abstract}
The RNA exosome was originally discovered in yeast as an RNA-processing complex required for the maturation of 5.8S ribosomal RNA (rRNA), one of the constituents of the large ribosomal subunit. The exosome is now known in eukaryotes as the major 3'-5' RNA degradation machine involved in numerous processing, turnover, and surveillance pathways, both in the nucleus and the cytoplasm. Yet its role in maturing the $5.8 \mathrm{~S}$ rRNA in the pre-60S ribosomal particle remains probably the most intricate and emblematic among its functions, as it involves all the RNA unwinding, degradation, and trimming activities embedded in this macromolecular complex. Here, we propose a comprehensive mechanistic model, based on current biochemical and structural data, explaining the dual functions of the nuclear exosome - the constructive versus the destructive mode.
\end{abstract}

The RNA exosome is a major $3^{\prime}-5^{\prime}$ exoribonuclease that targets a wide range of substrates in different cellular compartments in all eukaryotes studied to date (for reviews, see Chlebowski et al. 2013; Zinder and Lima 2017; Schmid and Jensen 2019). In RNA metabolism, the exosome may be considered as a "Dr. Jekyll and Mr. Hyde" complex: it can either trim or destroy (Fig. 1). For example, exosome-mediated degradation eliminates transfer RNAs (tRNAs) in the nucleus that are in excess or defective (Kadaba et al. 2004; Gudipati et al. 2012) and a myriad of transcripts generated from pervasive transcription such as cryptic unstable transcripts (CUTs) in yeast (LaCava et al. 2005; Wyers et al. 2005) or promoter upstream transcripts in human cells (PROMPTs) (Preker et al. 2008). Likewise, exosome-mediated degradation eliminates messenger RNAs (mRNAs) in the cytoplasm (for review, see Schaeffer et al. 2011). In contrast, in nuclear RNA biogenesis pathways the exosome partially and specifically trims ribosomal RNA (rRNA) and small nuclear/nucleolar RNA precursors (Mitchell et al. 1996, 1997; Allmang et al. 1999). Taken together, it is not surprising that mutations in the RNA exosome are associated with human pathologies, including autoimmune and neurodegenerative disorders (for reviews, see Staals and Pruijn 2011; Fasken et al. 2020).

Tremendous progress has been made in the past decade to decipher the properties, architecture, and interplay of the exosome and its cofactors, first using Saccharomyces cerevisiae as a model organism (Liu et al. 2006, 2016; Bonneau et al. 2009; Makino et al. 2013a, 2015; Wasmuth et al. 2014, 2017; Kowalinski et al. 2016; Zinder et al.
2016; Falk et al. 2017a) and lately the human orthologs (Gerlach et al. 2018; Weick et al. 2018). Strategies developed from biochemical and genetic studies to "immobilize" the exosome in defined functional states allowed visualization of different snapshots of this complex at near-atomic resolution. However, because of the technical challenges posed by the sheer size and complexity of the factors involved at both the protein and RNA levels, the molecular basis explaining how the exosome can function constructively in RNA processing pathways and destructively in RNA decay pathways has evaded the field. In the past few years, the "resolution revolution" in cryo-electron microscopy has contributed to important advancements, including visualization of not only the entire nuclear exosome holocomplex (Gerlach et al. 2018; Weick et al. 2018) but also the complex processing of rRNA from a precursor of the large ribosomal subunit (Schuller et al. 2018). In this review, we focus on individual structural snapshots and extrapolate possible mechanisms by which the nuclear exosome may execute its decay and processing functions.

\section{ARCHITECTURE OF THE RNA EXOSOME: THE CORE COMPLEX}

The RNA exosome is an ancient machine with prokaryotic ancestry that has been likened to a proteasome for RNA (for reviews, see van Hoof and Parker 1999; Lorentzen and Conti 2006; Makino et al. 2013b). In eukaryotes, the core complex is formed by 10 different subunits (Exo10) (Fig. 2). Studies in yeast and human revealed that

(C) 2019 Lingaraju et al. This article is distributed under the terms of the Creative Commons Attribution-NonCommercial License, which permits reuse and redistribution, except for commercial purposes, provided that the original author and source are credited. 


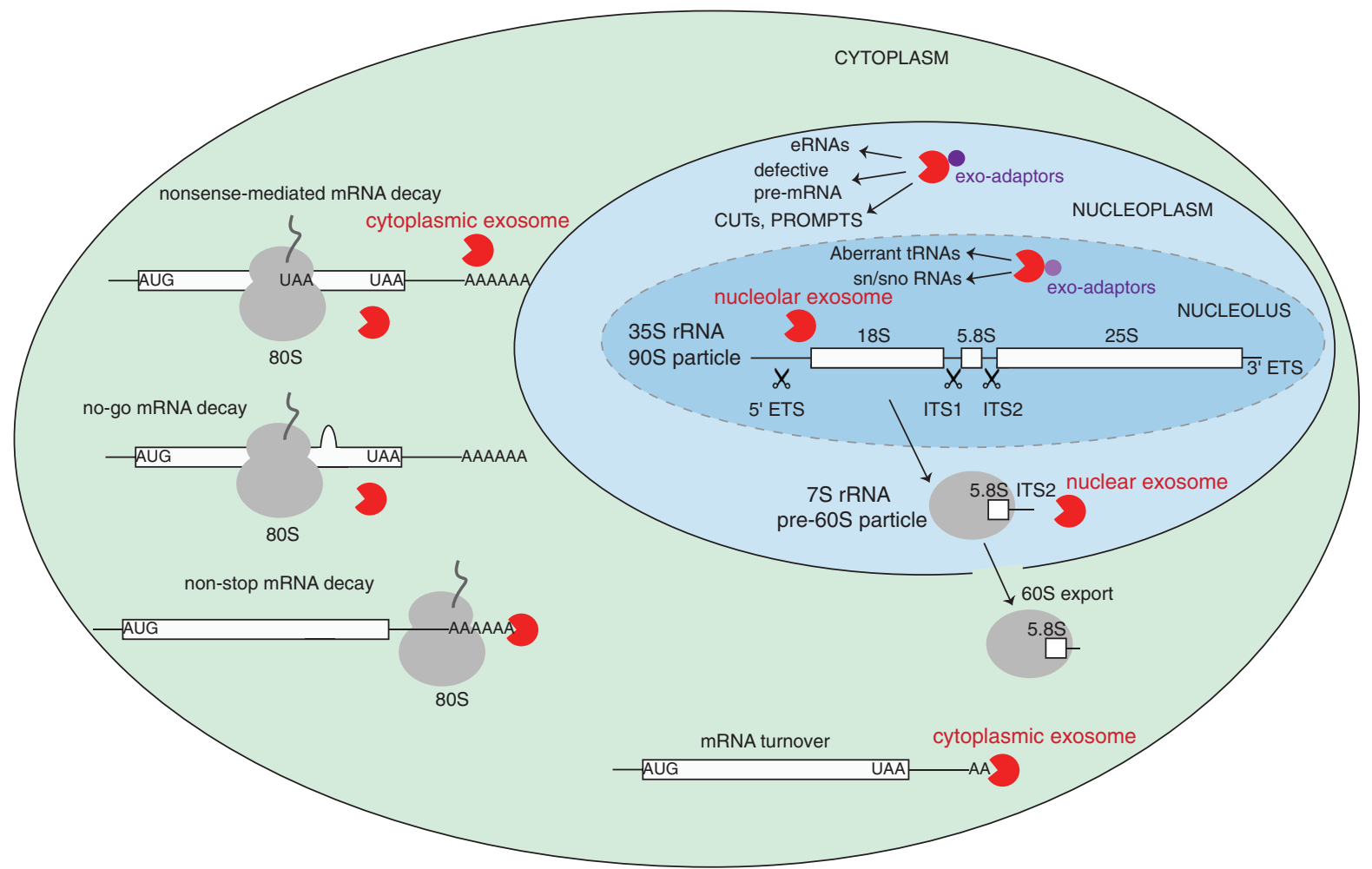

Figure 1. The exosome is a juggernaut in $3^{\prime}-5^{\prime}$ RNA degradation. The scheme shows a subset of the wide variety of RNA processing and degradation activities of the eukaryotic exosome (shown in red, with nuclear adaptor proteins represented in violet) in the nucleolus, the nucleoplasm, and the cytoplasm. In the nucleoplasm, the exosome is involved in the maturation of 5.8S rRNA and also interacts with several exosome adaptors to form complexes such as NEXT and PAXT to target various substrates (see also Puno et al. 2019). Endoribonucleolytic cleavages involved in ribosome processing (not involving the exosome) are indicated with scissors. Exosomemediated cytoplasmic pathways include mRNA turnover and translation-dependent surveillance pathways.

nine exosome subunits assemble into a barrel-like structure that lacks catalytic activity (Exo9) (Liu et al. 2006; Dziembowski et al. 2007). Exo9 is organized into an upper ring of three "cap" subunits (Rrp4, Rrp40, and Cs14) with $\mathrm{S} 1 / \mathrm{KH}$ domains similar to those found in RNA-binding proteins and a lower ring of six subunits with the fold typical of a bacterial $3^{\prime}-5^{\prime}$ ribonuclease, RNase $\mathrm{PH}$, but lacking functional active sites. The Exo9 barrel is traversed by a prominent central channel that spans from the narrow entry pore at the top of upper ring to the side of the lower ring adopting an L-shaped structure that has been conserved from the archaeal ancestor complex (Lorentzen et al. 2007; Bonneau et al. 2009). In eukaryotes, this internal channel feeds RNA substrates to the 10th subunit, the Rrp44 ribonuclease (also known as Dis3) (Makino et al. 2013a). The Rrp44 amino-terminal PIN domain provides the high-affinity binding that anchors Rrp44 to Exo9 (Bonneau et al. 2009) and in addition contains an accessible endonuclease active site (Lebreton et al. 2008; Schaeffer et al. 2009; Schneider et al. 2009; Han and van Hoof 2016). The carboxy-terminal domain of Rrp44 shares similar structural features to RNase II of Escherichia coli and degrades RNAs in the $3^{\prime}-5^{\prime}$ direction, cleaving one nucleotide at a time in a processive manner-that is, performing sequential rounds of cleavages without disso- ciating from the RNA substrate (Frazao et al. 2006; Lorentzen et al. 2008). This domain harbors the principal exoribonuclease activity of the exosome complex (Liu et al. 2006; Dziembowski et al. 2007). In S. cerevisiae, the RNase II-like domain of Rrp44 can swing from an open conformation (Bonneau et al. 2009; Makino et al. 2015) to a closed conformation oriented toward Exo9 to receive an RNA substrate coming from the central channel (Fig. 2A,B; Makino et al. 2013a). Biochemical and structural studies using a catalytically inactive Exo10 mutant have shown that the footprint of an RNA bound to the complex spans $\sim 30 \mathrm{nt}$ (Bonneau et al. 2009; Makino et al. 2013a). Data in yeast suggest that this internal channel serves as the major path used by exosome substrates in vivo (Schneider et al. 2012). Yeast Exo10 is largely similar in structure and function to its human counterpart, but with two important differences. First, in human cells there are two homologs of Rrp44-namely, DIS3 in the nucleus and DIS3L in the cytoplasmresulting in compartment-specific variants of the exosome core (Staals et al. 2010; Tomecki et al. 2010). Second, current data suggest that the DIS3 ribonuclease may retain an open conformation both in the unbound state and in the RNA-bound state, resulting in a slightly longer RNA channel than denoted in yeast (Gerlach et al. 2018; Weick et al. 2018). 
A

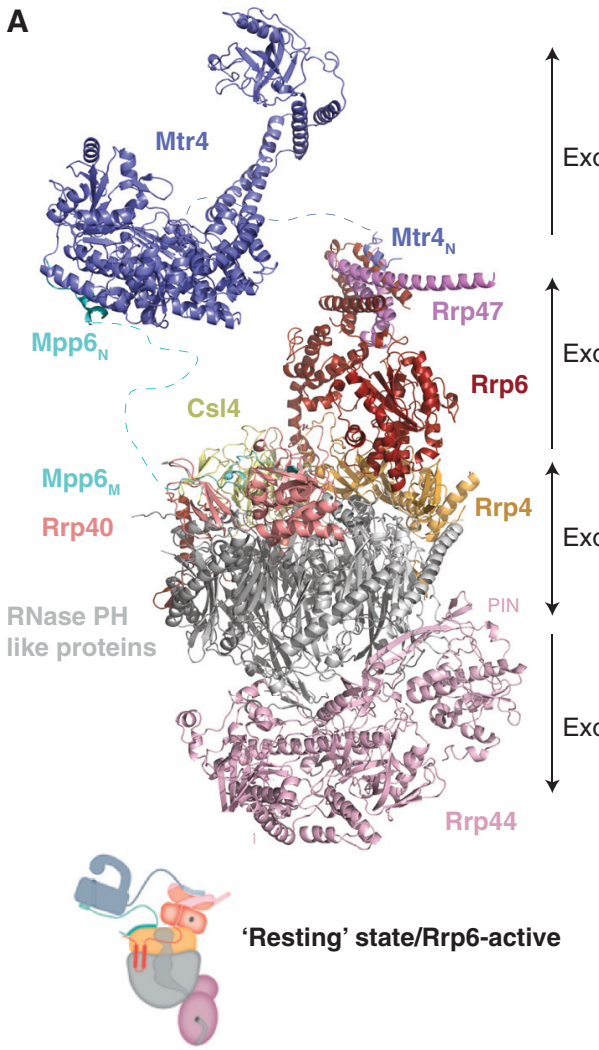

B

Exo14

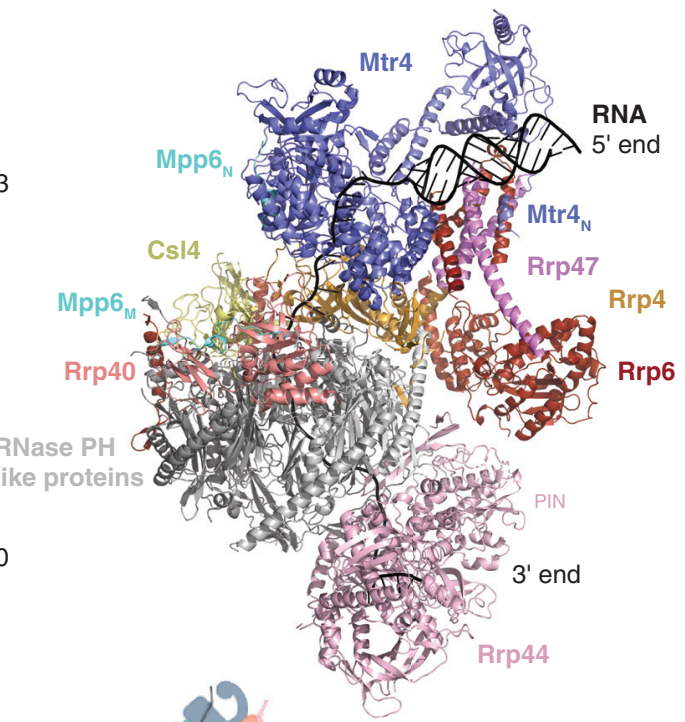

'Processing' state/Rrp44-active

Figure 2. Architecture of the nuclear exosome holocomplex: Exo14n. (A) Composite structure of eukaryotic Exo13n (cartoon representation) in resting mode and in distributive degradation mode (e.g., Rrp6-mediated). The model is a superposition of several crystal

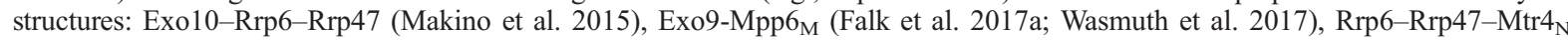
(Schuch et al. 2014), and the Rrp6-RNA exosome complex (Wasmuth et al. 2014). The helicase core of Mtr4 (Jackson et al. 2010; Weir et al. 2010) is shown in a hypothetical arrangement, linked to the Exo13n core by the interaction of the DExH core with Mpp6 $6_{\mathrm{N}}(\mathrm{Schuller}$ et al. 2018; Weick et al. 2018) and by the interaction of $M \operatorname{Mtr}_{\mathrm{N}}$ with the Rrp6 $6_{\mathrm{N}}-\operatorname{Rrp} 47_{\mathrm{N}}$ heterodimerization module (Schuch et al. 2014). $\mathrm{N}$ stands for amino-terminal domain; $\mathrm{M}$ for middle domain. The low-complexity carboxy-terminal sequences of Mpp6 and Rrp6 are flexible and not shown. Exo9: the upper ring of the S1/KH proteins is shown in warm colors (Cs14 in yellow, Rrp4 in orange and Rrp40 in salmon) and the lower ring of six RNase-PH like proteins in gray. The processive ribonuclease Rrp44 (light pink) is positioned at the lower ring of Exo9 (here in the open conformation without RNA). The nuclear cofactors Mpp6 (cyan), Rrp6 (red), Rrp47 (purple), and Mtr4 (blue) are at the top of the upper ring. A cartoon model of the nuclear exosome in the resting state/Rrp6 active state, corresponding to the cartoon model in Figure 5, is shown below. $(B)$ Composite structure of eukaryotic Exo14n (cartoon representation) in processive mode (i.e., Rrp44-mediated). The model is based on the cryo-EM structure of a pre-60S-bound complex (Schuller et al. 2018), the crystal

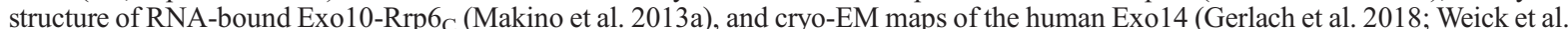
2018). The RNA is threaded through Mtr4 into the exosome central channel and to the Rrp44 ribonuclease (in closed conformation). A cartoon model of the nuclear exosome in the Rrp44 active state, corresponding to the cartoon model in Figure 5, is shown below.

\section{ARCHITECTURE OF THE RNA EXOSOME: THE NUCLEAR COFACTORS}

In the yeast nucleus, Exo10 associates with four conserved cofactors with physical interactions (Schuch et al. 2014) that are functionally important (for review, see Butler and Mitchell 2011) to form the nuclear exosome holocomplex (Exo14n). Purifications of the endogenous complex from yeast indicate that in vivo three of them (the nonprocessive ribonuclease Rrp6 and the small proteins Rrp47 and Mpp6) form a stable assembly with Exo10 (nuclear Exo13 or Exo13n), whereas the fourth cofactor, the Mtr4 helicase, appears to be more weakly or transiently incorporated into the nuclear exosome holocomplex (Falk et al. 2017a). All nuclear cofactors bind Exo9 at the top of the S1/KH ring, essentially on the opposite side with respect to Rrp44 (Fig. 2; Wasmuth et al. 2014; Makino et al. 2015; Falk et al. 2017a; Wasmuth et al. 2017). Rrp6 is organized into several distinct domains, each with specific functions. The amino-terminal domain of Rrp6 heterodimerizes with Rrp47 (Schuch et al. 2014). The carboxy-terminal region wraps around the cap subunit Csl4, providing the primary anchor to Exo9 (Makino et al. 2013a) and also contains a nuclear localization signal (Callahan and Butler 2008). The central region binds and degrades RNAs via its HRDC and DEDD domains, respectively (Midtgaard et al. 2006; Schuch et al. 2014; Zinder et al. 2016). The Rrp6 exoribonuclease activity cleaves single nucleotides in the $3^{\prime}-$ $5^{\prime}$ direction in a distributive manner (i.e., dissociating from the RNA substrate after each round of cleavage). The difference between the distributive properties of Rrp6 and the 
processive properties of Rrp44 can be reconciled with the geometry of their active site: shallow and exposed to solvent in the case of Rrp6 and buried in an internal channel in case of Rrp44. Although Rrp44 is the general and ubiquitous degradation engine of the exosome complex, Rrp6 appears to have trimming functions in the nucleus.

When the nuclear exosome holocomplex is in a resting state, the central exoribonuclease region of Rrp6 binds flat on top of cap subunit Rrp4 (Wasmuth et al. 2014; Zinder et al. 2016) and is in turn surmounted by the Rrp6-Rrp47 heterodimerization module (Makino et al. 2015). Mpp6 is an intrinsically disordered protein that binds with its central region to the third cap subunit, Rrp40 (Falk et al. 2017a; Wasmuth et al. 2017). Mpp6 and the Rrp6Rrp47 unit both contribute to recruiting RNA via their unstructured segments (Wasmuth et al. 2017) and both contribute to binding the Mtr4 helicase (Schuch et al. 2014; Falk et al. 2017a; Schuller et al. 2018; Weick et al. 2018). These observations explain the synthetic lethality of $\operatorname{rrp} 6 \Delta m p p 6 \Delta$ and of rrp474mpp6 6 strains (Milligan et al. 2008; Garland et al. 2013), as eliminating both Mtr4-anchor points would compromise the recruitment of this essential helicase.

Mtr4 is also a multidomain protein. At the amino terminus is an unstructured region that binds the concave surface of the Rrp6-Rrp47 heterodimerization module (Fig. 2A,B; Schuch et al. 2014). The carboxy-terminal region is structured and consists of two domains: the helicase DExH domain and the arch (also known as SK) domain (Jackson et al. 2010; Weir et al. 2010). The DExH domain is catalytically active in unwinding RNA substrates in an ATP-dependent manner; RNA enters at the top of the DExH core and the unwound 3' end exits at the base (Weir et al. 2010). The arch domain faces the entrance of the helicase channel at the top of the DExH core and contains a KOW domain capable of binding both singlestranded and structured RNAs (Jackson et al. 2010; Weir et al. 2010). In addition to RNA binding, both domains of Mtr4 serve as protein binding platforms: the DExH core, for example, binds the amino-terminal region of Mpp6 (Gerlach et al. 2018; Schuller et al. 2018 ; Weick et al. 2018), and the KOW domain binds so-called arch-interacting motifs (AIMs) of adaptor proteins, such as in the ribosomal biogenesis factor Nop53 (Thoms et al. 2015; Falk et al. 2017b; Lingaraju et al. 2019). The essential unwinding activity of Mtr4 likely serves to prepare substrates for threading into the narrow entry pore of the exosome core, which is only wide enough to accommodate single-stranded RNA substrates (Makino et al. 2013a).

\section{MECHANISTIC MODEL OF THE EXOSOME IN ITS RNA DECAY FUNCTION}

Based on structures determined through X-ray crystallography and cryo-electron microscopy (cryo-EM) as well as biochemical data (Makino et al. 2013a, 2015; Wasmuth et al. 2014, 2017; Zinder et al. 2016; Falk et al. 2017a; Gerlach et al. 2018; Weick et al. 2018), we can propose the molecular mechanisms with which the nuclear exosome processively degrades and thus eliminates RNA substrates. The working model posits that when an RNA or ribonucleoprotein (RNP) substrate is recruited to Mtr4 or to an Mtr4-adaptor complex, the helicase activity of Mtr4 unwinds the RNA substrate, thus progressively extruding the unwound 3' end toward the top of Exo13n, where Mtr4 is loosely positioned through its interactions with Rrp6Rrp47 and Mpp6. In Exo13n, the RNA 3' end will first encounter the active site of Rrp6 and stochastically be degraded in a distributive manner before getting threaded into Exo9 and channeled to the processive site of Rrp44.

As Mtr4 productively engages with an RNA substrate and Exo14n reaches its processive degradation mode, the helicase core displaces the nuclease domain of Rrp6 by competing for the same binding site on Exo10, the cap subunit Rrp4 (Fig. 2B). The amino-terminal Rrp6-Rrp47 heterodimerization module also changes its position drastically, as it detaches from the nuclease domain of Rrp6 to interact with the arch domain of Mtr4. The helicase adopts a peculiar edge-on conformation, with the base of the DExH domain tilted at an $\sim 45^{\circ}$ angle with respect to the top of the exosome core. In this conformation, the RNA 3' end exiting from the base of the DExH domain of Mtr4 is guided to the entry pore of the Exo10 channel. The overall path of an RNA entering the helicase channel of Mtr4 and continuing into the central channel of Exo10 in a singlestranded conformation has a footprint of $\sim 40$ nt (Falk et al. 2017a). The processive mode of Exo14n results in a final product of 4 nt (i.e., in the degradation of almost the entire transcript).

Interestingly, the Mtr4 conformation on top of the exosome core and the threading RNA observed not only in structures of the yeast complex (Schuller et al. 2018) but also in the human complex (Gerlach et al. 2018; Weick et al. 2018) suggest the mechanism and conformational regulation are evolutionarily conserved aspects of the nuclear exosome. The proposed mechanism is expected to lead to complete decay of any substrate unwound by Mtr4. Effectively, this appears to be the case for most RNA substrates, including structured transcripts such as tRNAs, with the notable exception of the $5.8 \mathrm{~S}$ rRNA during pre$60 \mathrm{~S}$ biogenesis.

\section{CONSTRUCTIVE FUNCTION OF THE RNA EXOSOME IN RIBOSOMAL RNA PROCESSING}

During the biogenesis and maturation of the pre-60S subunit, the nuclear exosome recognizes a massive ribonucleoprotein particle at a specific maturation stage, remodels it, and dissociates when the rRNA has been trimmed to a precise point. The exosome specifically recognizes the pre-60S particles at the 7S rRNA maturation stage. The 7S rRNA is a 5.8S rRNA precursor with a 3 '-end extension of $\sim 140 \mathrm{nt}$ that is generated by an upstream endonucleolytic cleavage in the internal transcribed spacer 2 (ITS2) (Thomson et al. 2013; Woolford and Baserga 2013; Gasse et al. 2015; Turowski and Toll- 
ervey 2015). The 7S rRNA is trimmed by the sequential action of the two nuclear exosome ribonucleases, Rrp44 and Rrp6 (Fig. 3). In the first step, Rrp44 shortens the 7S rRNA to form a $5.8 \mathrm{~S}$ precursor carrying a 30-nt 3 ' extension $(5.8 \mathrm{~S}+30)$ (Briggs et al. 1998). This intermediate is then shortened by Rrp6 to form the $6 \mathrm{~S}$ rRNA (a 5.8S with a 6- to 8-nt 3' extension), which is then exported to the cytoplasm for the final trimming (Thomson and Tollervey 2010). Notably, the +30 -nt RNA processing defect of 5.8S rRNA in Rrp6 $\Delta$ strains (Briggs et al. 1998) matches the footprint of the 30-nt path of Exo10 in vitro (Bonneau et al. 2009; Makino et al. 2013a). Human cells have a similar 5.8S +40 intermediate (Tafforeau et al. 2013), again consistent with the longer footprint of the human exosome core in vitro (Gerlach et al. 2018).

The specificity with which the exosome ribonucleases recognize different pre-rRNA substrates and the accuracy with which they stop degrading at specific positions in the transcripts have long remained a mystery, particularly because the end points do not correlate with the presence of structured elements in the rRNA. An important aspect of this process is that the rRNA precursors are not trimmed in isolation, but in the context of RNPs that also contain ribosomal proteins and ribosome assembly factors. Cryo-EM reconstructions of pre-60S biogenesis intermediate at the 7S maturation stage have shown how the ITS2 RNP forms the so-called "foot structure" of the pre-60S. The "foot structure" contains $\sim 60$ nt of ITS2 folded into an intertwined RNA structure bound by several ribosomal assembly factors, including Nop53 and Nop7 (Fig. 4A; Wu et al. 2016). The remaining $\sim 80 \mathrm{nt}$ of ITS2 is presumably extended into solvent as is the amino-terminal region of Nop53, which has been shown to recruit the Mtr4 helicase (Thoms et al. 2015; Falk et al. 2017b; Fromm et al. 2017). Thus, the two elements of the pre-60S particle that are recognized by the RNA exosome (the 7S 3' end and amino terminus of Nop53) are exposed to solvent and accessible to the RNA processing machinery.

\section{MECHANISTIC MODEL OF THE NUCLEAR EXOSOME IN ITS RNA PROCESSING FUNCTION}

In light of the published data, we propose the following model. We envision an initial recognition step in the precise processing of $5.8 \mathrm{~S}$ rRNA precursor where the Mtr4 arch domain binds the flexible amino-terminal region of Nop53 (Thoms et al. 2015; Wu et al. 2016) and threads the accessible 3' RNA extension of ITS2 into the helicase channel. Once Mtr4 is loaded with its physiological RNA substrate, it can "hand over" the RNA to the Rrp44 activity in the exosome (Figs. 4B and 5-II), presumably with a similar sequence of steps described for the processive degradative activity above. The main difference is that at this stage the 7S rRNA is likely to bypass the Rrp6 active site altogether: the endonucleolytic cleavage that generates the $7 \mathrm{~S}$ rRNA leaves a 2',3'-cyclic phosphate at the $3^{\prime}$ end of the exosome substrate (Gasse et al. 2015), and such a modified $3^{\prime}$ end is unlikely to fit the geometry of the Rrp6 active site (our unpubl. observations). In contrast, the active site of Rrp44 is larger and can, in principle, accommodate a $2^{\prime}, 3^{\prime}$-cyclic phosphate (Meaux and van Hoof 2006; Zinder et al. 2016). As the 3' end of the 7S rRNA reaches the active site of Rrp44 and

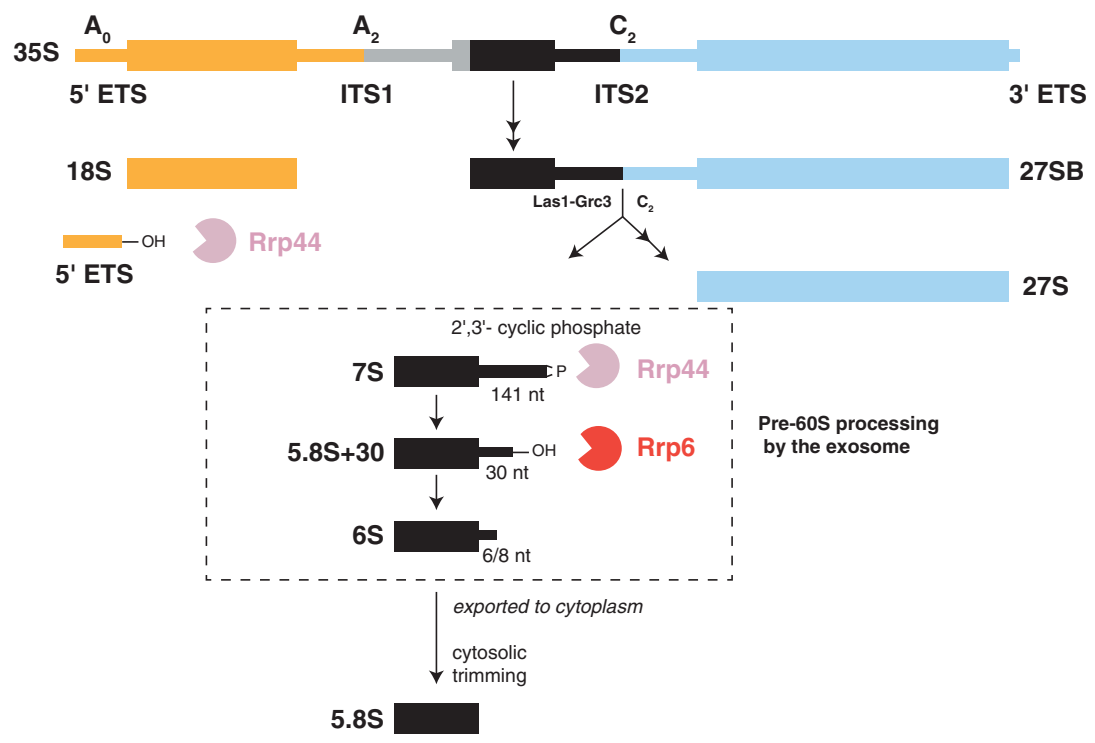

Figure 3. Scheme of yeast rRNA processing. The ribosomal pre-rRNA is transcribed as a single long polycistronic transcript, the $35 \mathrm{~S}$ rRNA precursor that contains the 5'-ETS region (light orange-thin rectangle), the 18S rRNA (light orange-thick rectangle), the ITS1 (internal transcribed spacer region), 5.8S rRNA (black), ITS2, 25S rRNA (light blue), and the 3' ETS. The 5'-ETS sequence after cleavage at the $\mathrm{A}_{0}$ site is degraded in an Mtr4-dependent manner by the nuclear RNA exosome. For 5.8S maturation, the 27SB pre-rRNA is cleaved at site $\mathrm{C} 2$ by the Las 1 endonuclease complex, yielding a 3' RNA with a 2',3'-cyclic phosphate. The resulting product is first processed by the processive action of Rrp44 (pink) (degrades about $110 \mathrm{nt}$ ) to yield the $5.8 \mathrm{~S}+30$ intermediate, followed by the distributive action of the Rrp6 (red) ribonuclease. (The scheme is adapted from Schuller et al. 2018.) 
A

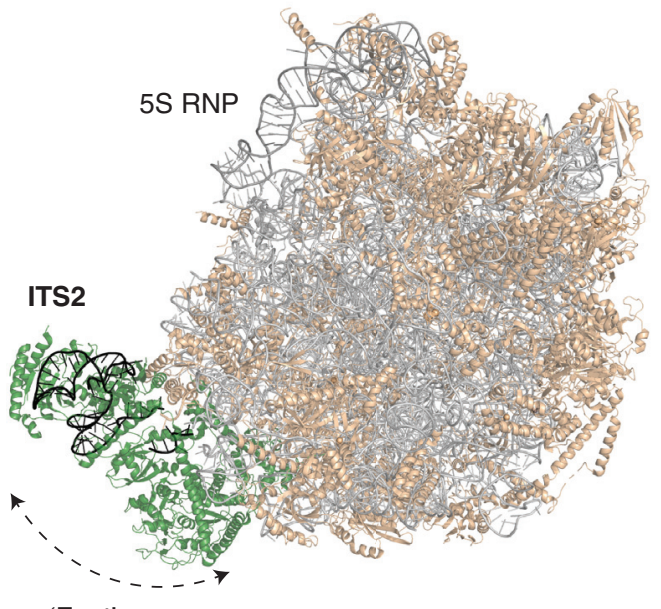

'Foot'

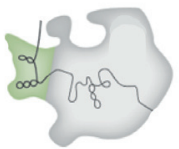

25S rRNA/5S rRNA

5 S RNP

Biogenesis factors (Nop7, Nop15, Nop53, Rlp7, Cic1)

605 proteins and assembly factors

B

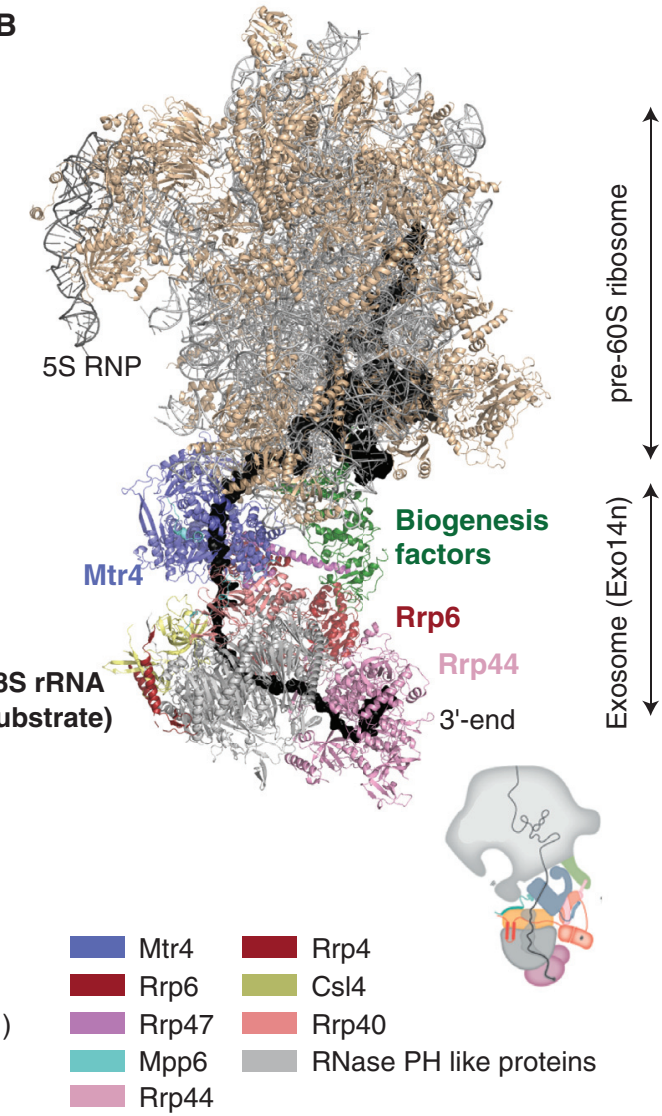

Figure 4. Nuclear exosome in preribosome processing. (A) Cartoon representation of the cryo-EM structure of a 7S pre-60S substrate (Wu et al. 2016) showing the foot structure that is remodeled by the exosome. (B) Cartoon representation of the cryo-EM structure of Exo14n determined by "immobilizing" the complex on a 7S pre-60S substrate at the $5.8 \mathrm{~S}+30$ intermediate state using an Rrp6 active site mutant (Schuller et al. 2018). The pre-60S is shown with ribosomal proteins in wheat, the 5.8S rRNA in black, the 25S rRNA and 5S rRNAs in gray, ribosomal biogenesis factors in green, and the exosome components are colored similarly as in Figure 2. Below each panel are the corresponding cartoon models as they appear in Figure 5.

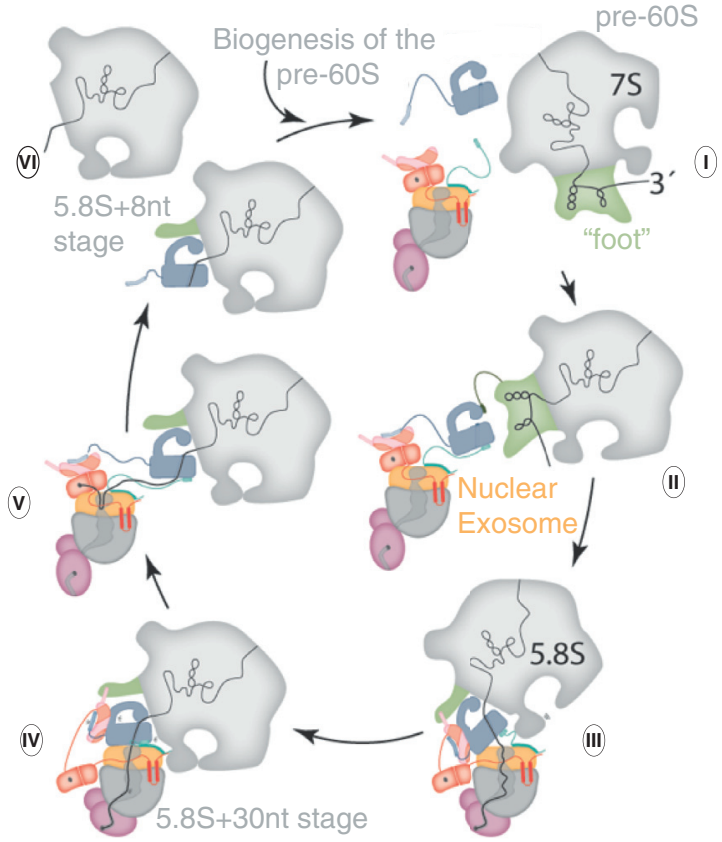

Figure 5. Model of exosome-mediated pre-60S particle processing. Schematic representation depicting the compositional and conformational rearrangements during 5.8S rRNA maturation. The steps show the recruitment to the 7S particle via the Nop53-Mtr4 interaction (III); the processive degradation step, resulting in remodeling of the ITS2 and associated factors (the "foot" structure, II-III); the 5.8S +30 particle as a transient state where Mtr4 adopts a strained highenergy position on Exo9 (IV); the distributive trimming step after Mtr4 releases the RNA from the exosome channel (V). In this model, Rrp6 can degrade the $5.8 \mathrm{~S}$ extension up to $6-8 \mathrm{nt}$ (6S rRNA), which is then exported to the cytoplasm. 
starts to be processively degraded, Mtr4 can unwind the rest of ITS2.

Almost all the ribosome biogenesis factors in the foot structure are removed at this stage (Fromm et al. 2017; Schuller et al. 2018), including Nop53, the factor that initially recruited Mtr4 (Thoms et al. 2015). Mtr4, however, forms other contacts with the pre-60S as the foot structure is remodeled: the KOW domain and the DExH core bind the $25 \mathrm{~s}$ rRNA at domain I and domain V, respectively (Schuller et al. 2018). The only biogenesis factor to remain in the foot structure at this stage is Nop7, which engages in an interaction with the carboxy-terminal helix of Rrp47 (Schuller et al. 2018) (Fig. 4B). Exo14n is expected to degrade the ITS2 extension from 110 to $\sim 40 \mathrm{nt}$ in the processive conformation, generating a $3{ }^{\prime}-\mathrm{OH}$ end that is compatible with both Rrp6 and Rrp44 (Fig. 5-III). However, further degradation by Rrp44 is predicted to result in substantial deformation. The sheer mass of the pre-60S would likely compress Exo14n and, in particular, Mtr4 from its resting edge-on conformation to a strained flaton conformation on the exosome core (Fig. 5-IV). Based on in vivo data (Briggs et al. 1998), the strain on Exo14n will likely reach its limit at $30 \mathrm{nt}$, when further compaction is physically not possible. At this point, we speculate that the strained arch domain may flip the helicase from the top of Exo13n, simultaneously ejecting the remaining $30 \mathrm{nt}$ of the 5.8S rRNA extension from the exosome channel and rendering them accessible to Rrp6 (Fig. 5-V).

We envision that in the distributive step, Rrp6 is repositioned on top of the exosome core (Zinder et al. 2016). Degradation by Rrp6 at the last 6-8 nt will likely stop upon encountering a physical block, possibly by clashing against the helicase Mtr4 that could still be docked onto the ribosome and bound to the 5.8S rRNA extension at this step. The model implicates that Mtr4 might have to be actively removed from the large ribosomal subunit and the $3^{\prime}$ end before it is exported to the cytoplasm (Fig. 5-VI). How this could be achieved remains unclear, although it is possible that it involves the action of one of the $\mathrm{AAA}^{+}$ATPases that are involved in remodeling steps of the preribosomal particles.

\section{CONCLUSION}

The biochemical and structural studies to date support the notion proposed a decade ago (Bonneau et al. 2009) that the exosome core functions as a macromolecular cage to channel RNA substrates for degradation. The entrance to the cage is gated by cofactors that either limit or grant access to the central degradation channel. In its resting state in the nucleus, Rrp6 regulates the access to the processive ribonuclease of the complex. In the processive degradation mode, when Mtr4 is loaded with an RNA, the ATPase displaces the negative regulator with a large conformational change and injects the substrate into the processive degradation channel. This central channel of the exosome is used for both RNA decay and for 5.8S rRNA processing. The difference between complete and partial degradation resides in the physical constraints im- posed by the substrate, a very large and complex RNP particle in the case of 5.8S rRNA processing. Looking back, the exosome was thus discovered (Mitchell et al. 1997) by studying the exception (partial degradation and processing) to the rule (complete degradation and decay). Looking forward, we expect that the exosome may integrate additional layers of negative regulation to avoid unleashing uncontrolled degradation. Given the crucial roles of Mtr4 in providing the substrate remodeling activity and in providing a hub for interacting adaptor proteins, it is reasonable to expect regulation at this pivotal intersection to target RNA substrate to the RNA exosome. Unraveling exosome helicase regulation will be an important avenue of future research.

\section{ACKNOWLEDGMENTS}

We are grateful to Courtney Long and members of the group for input and discussion on the manuscript. We also thank Sandra Schuller for the models and the drawings in Figure 5. This study was supported by funding from the Max-Planck-Gesellschaft, the European Commission (ERC Advanced Investigator Grant EXORICO), and the German Research Foundation (DFG SFB1035, GRK1721, SFB/TRR 237) to E.C. and a Boehringer Ingelheim Fonds fellowship to M.L.

\section{REFERENCES}

Allmang C, Kufel J, Chanfreau G, Mitchell P, Petfalski E, Tollervey D. 1999. Functions of the exosome in rRNA, snoRNA and snRNA synthesis. EMBO J 18: 5399-5410. doi:10.1093/ emboj/18.19.5399

Bonneau F, Basquin J, Ebert J, Lorentzen E, Conti E. 2009. The yeast exosome functions as a macromolecular cage to channel RNA substrates for degradation. Cell 139: 547-559. doi:10 .1016/j.cell.2009.08.042

Briggs MW, Burkard KT, Butler JS. 1998. Rrp6p, the yeast homologue of the human PM-Scl 100-kDa autoantigen, is essential for efficient 5.8 S rRNA 3' end formation. J Biol Chem 273: 13255-13263. doi:10.1074/jbc.273.21.13255

Butler JS, Mitchell P. 2011. Rrp6, rrp47 and cofactors of the nuclear exosome. Adv Exp Med Biol 702: 91-104. doi:10 .1007/978-1-4419-7841-7 8

Callahan KP, Butler JS. 2008. Evidence for core exosome independent function of the nuclear exoribonuclease Rrp6p. $\mathrm{Nu}$ cleic Acids Res 36: 6645-6655. doi:10.1093/nar/gkn743

Chlebowski A, Lubas M, Jensen TH, Dziembowski A. 2013. RNA decay machines: the exosome. Biochim Biophys Acta 1829: 552-560. doi:10.1016/j.bbagrm.2013.01.006

Dziembowski A, Lorentzen E, Conti E, Séraphin B. 2007. A single subunit, Dis3, is essentially responsible for yeast exosome core activity. Nat Struct Mol Biol 14: 15-22. doi:10.1038/ nsmb1184

Falk S, Bonneau F, Ebert J, Kogel A, Conti E. 2017a. Mpp6 incorporation in the nuclear exosome contributes to RNA channeling through the Mtr4 helicase. Cell Rep 20: 2279 2286. doi:10.1016/j.celrep.2017.08.033

Falk S, Tants JN, Basquin J, Thoms M, Hurt E, Sattler M, Conti E. 2017b. Structural insights into the interaction of the nuclear exosome helicase Mtr4 with the preribosomal protein Nop53. RNA 23: 1780-1787. doi:10.1261/rna.062901.117

Fasken MB, Morton DJ, Kuiper EG, Jones SK, Leung SW, Corbett AH. 2020. The RNA exosome and human disease. Methods Mol Biol 2062: 3-33. doi:10.1007/978-1-4939-9822-7_1 
Frazao C, McVey CE, Amblar M, Barbas A, Vonrhein C, Arraiano CM, Carrondo MA. 2006. Unravelling the dynamics of RNA degradation by ribonuclease II and its RNA-bound complex. Nature 443: 110-114. doi:10.1038/nature05080

Fromm L, Falk S, Flemming D, Schuller JM, Thoms M, Conti E, Hurt E. 2017. Reconstitution of the complete pathway of ITS2 processing at the pre-ribosome. Nat Commun 8: 1787. doi:10 .1038/s41467-017-01786-9

Garland W, Feigenbutz M, Turner M, Mitchell P. 2013. Rrp47 functions in RNA surveillance and stable RNA processing when divorced from the exoribonuclease and exosome-binding domains of Rrp6. RNA 19: 1659-1668. doi:10.1261/rna .039388 .113

Gasse L, Flemming D, Hurt E. 2015. Coordinated ribosomal ITS2 RNA processing by the Las1 complex integrating endonuclease, polynucleotide kinase, and exonuclease activities. Mol Cell 60: 808-815. doi:10.1016/j.molcel.2015.10.021

Gerlach P, Schuller JM, Bonneau F, Basquin J, Reichelt P, Falk S, Conti E. 2018. Distinct and evolutionary conserved structural features of the human nuclear exosome complex. eLife 7: e38686. doi:10.7554/eLife.38686

Gudipati RK, Xu Z, Lebreton A, Séraphin B, Steinmetz LM, Jacquier A, Libri D. 2012. Extensive degradation of RNA precursors by the exosome in wild-type cells. Mol Cell 48: 409-421. doi:10.1016/j.molcel.2012.08.018

Han J, van Hoof A. 2016. The RNA exosome channeling and direct access conformations have distinct in vivo functions. Cell Rep 16: 3348-3358. doi:10.1016/j.celrep.2016.08.059

Jackson RN, Klauer AA, Hintze BJ, Robinson H, van Hoof A, Johnson SJ. 2010. The crystal structure of Mtr4 reveals a novel arch domain required for rRNA processing. $E M B O J$ 29: 2205-2216. doi:10.1038/emboj.2010.107

Kadaba S, Krueger A, Trice T, Krecic AM, Hinnebusch AG, Anderson J. 2004. Nuclear surveillance and degradation of hypomodified initiator tRNA ${ }^{\mathrm{Met}}$ in S. cerevisiae. Genes Dev 18: 1227-1240. doi:10.1101/gad.1183804

Kowalinski E, Kogel A, Ebert J, Reichelt P, Stegmann E, Habermann B, Conti E. 2016. Structure of a cytoplasmic 11-subunit RNA exosome complex. Mol Cell 63: 125-134. doi:10 $.1016 /$ j.molcel.2016.05.028

LaCava J, Houseley J, Saveanu C, Petfalski E, Thompson E, Jacquier A, Tollervey D. 2005. RNA degradation by the exosome is promoted by a nuclear polyadenylation complex. Cell 121: 713-724. doi:10.1016/j.cell.2005.04.029

Lebreton A, Tomecki R, Dziembowski A, Séraphin B. 2008. Endonucleolytic RNA cleavage by a eukaryotic exosome. $\mathrm{Na}$ ture 456: 993-996. doi:10.1038/nature 07480

Lingaraju M, Johnsen D, Schlundt A, Langer LM, Basquin J, Sattler M, Heick Jensen T, Falk S, Conti E. 2019. The MTR4 helicase recruits nuclear adaptors of the human RNA exosome using distinct arch-interacting motifs. Nat Commun 10: 3393. doi:10.1038/s41467-019-11339-x

Liu Q, Greimann JC, Lima CD. 2006. Reconstitution, activities, and structure of the eukaryotic RNA exosome. Cell 127: 1223-1237. doi:10.1016/j.cell.2006.10.037

Liu JJ, Niu CY, Wu Y, Tan D, Wang Y, Ye MD, Liu Y, Zhao W, Zhou K, Liu QS, et al. 2016. CryoEM structure of yeast cytoplasmic exosome complex. Cell Res 26: 822-837. doi:10 $.1038 / \mathrm{cr} .2016 .56$

Lorentzen E, Conti E. 2006. The exosome and the proteasome: nano-compartments for degradation. Cell 125: 651-654. doi:10.1016/j.cell.2006.05.002

Lorentzen E, Dziembowski A, Lindner D, Séraphin B, Conti E. 2007. RNA channelling by the archaeal exosome. EMBO Rep 8: $470-476$. doi: $10.1038 /$ sj.embor.7400945

Lorentzen E, Basquin J, Tomecki R, Dziembowski A, Conti E. 2008. Structure of the active subunit of the yeast exosome core, Rrp44: diverse modes of substrate recruitment in the RNase II nuclease family. Mol Cell 29: 717-728. doi:10.1016/j.molcel .2008 .02 .018

Makino DL, Baumgartner M, Conti E. 2013a. Crystal structure of an RNA-bound 11-subunit eukaryotic exosome complex. $\mathrm{Na}$ ture 495: 70-75. doi: 10.1038 /nature 11870
Makino DL, Halbach F, Conti E. 2013b. The RNA exosome and proteasome: common principles of degradation control. Nat Rev Mol Cell Biol 14: 654-660. doi:10.1038/nrm3657

Makino DL, Schuch B, Stegmann E, Baumgartner M, Basquin C, Conti E. 2015. RNA degradation paths in a 12-subunit nuclear exosome complex. Nature 524: 54-58. doi:10.1038/ nature 14865

Meaux S, van Hoof A. 2006. Yeast transcripts cleaved by an internal ribozyme provide new insight into the role of the cap and poly(A) tail in translation and mRNA decay. RNA 12: 1323-1337. doi:10.1261/rna.46306

Midtgaard SF, Assenholt J, Jonstrup AT, Van LB, Jensen TH, Brodersen DE. 2006. Structure of the nuclear exosome component Rrp6p reveals an interplay between the active site and the HRDC domain. Proc Natl Acad Sci 103: 11898-11903. doi:10.1073/pnas.0604731103

Milligan L, Decourty L, Saveanu C, Rappsilber J, Ceulemans H, Jacquier A, Tollervey D. 2008. A yeast exosome cofactor, Mpp6, functions in RNA surveillance and in the degradation of noncoding RNA transcripts. Mol Cell Biol 28: 5446-5457. doi:10.1128/MCB.00463-08

Mitchell P, Petfalski E, Tollervey D. 1996. The 3' end of yeast 5.8S rRNA is generated by an exonuclease processing mechanism. Genes Dev 10: 502-513. doi:10.1101/gad.10.4.502

Mitchell P, Petfalski E, Shevchenko A, Mann M, Tollervey D. 1997. The exosome: a conserved eukaryotic RNA processing complex containing multiple $3^{\prime} \rightarrow 5^{\prime}$ exoribonucleases. Cell 91 : 457-466. doi:10.1016/S0092-8674(00)80432-8

Preker P, Nielsen J, Kammler S, Lykke-Andersen S, Christensen MS, Mapendano CK, Schierup MH, Jensen TH. 2008. RNA exosome depletion reveals transcription upstream of active human promoters. Science 322: 1851-1854. doi:10.1126/sci ence. 1164096

Puno MR, Weick EM, Das M, Lima CD. 2019. SnapShot: the RNA exosome. Cell 179: 282.e1. doi:10.1016/j.cell.2019 .09 .005

Schaeffer D, Tsanova B, Barbas A, Reis FP, Dastidar EG, Sanchez-Rotunno M, Arraiano CM, van Hoof A. 2009. The exosome contains domains with specific endoribonuclease, exoribonuclease and cytoplasmic mRNA decay activities. Nat Struct Mol Biol 16: 56-62. doi:10.1038/nsmb.1528

Schaeffer D, Clark A, Klauer AA, Tsanova B, van Hoof A. 2011. Functions of the cytoplasmic exosome. Adv Exp Med Biol 702: 79-90. doi:10.1007/978-1-4419-7841-7_7

Schmid M, Jensen TH. 2019. The nuclear RNA exosome and its cofactors. Adv Exp Med Biol 1203: 113-132. doi:10.1007/ 978-3-030-31434-7_4

Schneider C, Leung E, Brown J, Tollervey D. 2009. The N-terminal PIN domain of the exosome subunit Rrp44 harbors endonuclease activity and tethers Rrp44 to the yeast core exosome. Nucleic Acids Res 37: 1127-1140. doi:10.1093/nar/ gkn1020

Schneider C, Kudla G, Wlotzka W, Tuck A, Tollervey D. 2012. Transcriptome-wide analysis of exosome targets. Mol Cell 48: 422-433. doi:10.1016/j.molcel.2012.08.013

Schuch B, Feigenbutz M, Makino DL, Falk S, Basquin C, Mitchell P, Conti E. 2014. The exosome-binding factors Rrp6 and Rrp47 form a composite surface for recruiting the Mtr4 helicase. EMBO J 33: 2829-2846. doi:10.15252/embj.201488757

Schuller JM, Falk S, Fromm L, Hurt E, Conti E. 2018. Structure of the nuclear exosome captured on a maturing preribosome. Science 360: 219-222. doi:10.1126/science.aar5428

Staals RH, Pruijn GJ. 2011. The human exosome and disease. Adv Exp Med Biol 702: 132-142. doi:10.1007/978-1-44197841-7 11

Staals RH, Bronkhorst AW, Schilders G, Slomovic S, Schuster G, Heck AJ, Raijmakers R, Pruijn GJ. 2010. Dis3-like 1: a novel exoribonuclease associated with the human exosome. EMBOJ 29: 2358-2367. doi:10.1038/emboj.2010.122

Tafforeau L, Zorbas C, Langhendries JL, Mullineux ST, Stamatopoulou V, Mullier R, Wacheul L, Lafontaine DL. 2013. The complexity of human ribosome biogenesis revealed by system- 
atic nucleolar screening of pre-rRNA processing factors. $\mathrm{Mol}$ Cell 51: 539-551. doi:10.1016/j.molcel.2013.08.011

Thoms M, Thomson E, Bassler J, Gnadig M, Griesel S, Hurt E. 2015. The exosome is recruited to RNA substrates through specific adaptor proteins. Cell 162: 1029-1038. doi:10.1016/ j.cell.2015.07.060

Thomson E, Tollervey D. 2010. The final step in 5.8S rRNA processing is cytoplasmic in Saccharomyces cerevisiae. Mol Cell Biol 30: 976-984. doi:10.1128/MCB.01359-09

Thomson E, Ferreira-Cerca S, Hurt E. 2013. Eukaryotic ribosome biogenesis at a glance. $J$ Cell Sci 126: 4815-4821. doi:10 $.1242 /$ jcs. 111948

Tomecki R, Kristiansen MS, Lykke-Andersen S, Chlebowski A, Larsen KM, Szczesny RJ, Drazkowska K, Pastula A, Andersen JS, Stepien PP, et al. 2010. The human core exosome interacts with differentially localized processive RNases: hDIS3 and hDIS3L. EMBO J 29: 2342-2357. doi:10.1038/emboj.2010 .121

Turowski TW, Tollervey D. 2015. Cotranscriptional events in eukaryotic ribosome synthesis. Wiley Interdiscip Rev RNA 6: 129-139. doi:10.1002/wrna.1263

van Hoof A, Parker R. 1999. The exosome: a proteasome for RNA? Cell 99: 347-350. doi:10.1016/S0092-8674(00) 81520-2

Wasmuth EV, Januszyk K, Lima CD. 2014. Structure of an Rrp6RNA exosome complex bound to poly(A) RNA. Nature 511: 435-439. doi:10.1038/nature13406

Wasmuth EV, Zinder JC, Zattas D, Das M, Lima CD. 2017. Structure and reconstitution of yeast Mpp6-nuclear exosome complexes reveals that Mpp6 stimulates RNA decay and re- cruits the Mtr4 helicase. eLife 6: e29062. doi:10.7554/eLife .29062

Weick EM, Puno MR, Januszyk K, Zinder JC, DiMattia MA, Lima CD. 2018. Helicase-dependent RNA decay illuminated by a cryo-EM structure of a human nuclear RNA exosomeMTR4 complex. Cell 173: 1663-1677 e1621. doi:10.1016/j cell.2018.05.041

Weir JR, Bonneau F, Hentschel J, Conti E. 2010. Structural analysis reveals the characteristic features of Mtr4, a DExH helicase involved in nuclear RNA processing and surveillance. Proc Natl Acad Sci 107: 12139-12144. doi:10.1073/pnas .1004953107

Woolford JL Jr, Baserga SJ. 2013. Ribosome biogenesis in the yeast Saccharomyces cerevisiae. Genetics 195: 643-681. doi:10.1534/genetics.113.153197

Wu S, Tutuncuoglu B, Yan K, Brown H, Zhang Y, Tan D, Gamalinda M, Yuan Y, Li Z, Jakovljevic J, et al. 2016. Diverse roles of assembly factors revealed by structures of late nuclear pre-60S ribosomes. Nature 534: 133-137. doi:10.1038/nature17942

Wyers F, Rougemaille M, Badis G, Rousselle JC, Dufour ME, Boulay J, Regnault B, Devaux F, Namane A, Séraphin B, et al. 2005. Cryptic pol II transcripts are degraded by a nuclear quality control pathway involving a new poly(A) polymerase. Cell 121: 725-737. doi:10.1016/j.cell.2005.04.030

Zinder JC, Lima CD. 2017. Targeting RNA for processing or destruction by the eukaryotic RNA exosome and its cofactors. Genes Dev 31: 88-100. doi:10.1101/gad.294769.116

Zinder JC, Wasmuth EV, Lima CD. 2016. Nuclear RNA exosome at $3.1 \AA$ reveals substrate specificities, RNA paths, and allosteric inhibition of Rrp44/Dis3. Mol Cell 64: 734-745. doi:10 .1016/j.molcel.2016.09.038 


\section{$\$_{\mathrm{CSH}}^{\infty}$ Cold Spring Harbor Symposia SYMPOSIA on Quantitative Biology}

\section{To Process or to Decay: A Mechanistic View of the Nuclear RNA Exosome}

Mahesh Lingaraju, Jan M. Schuller, Sebastian Falk, et al.

Cold Spring Harb Symp Quant Biol published online June 3, 2020

Access the most recent version at doi:10.1101/sqb.2019.84.040295

$\mathbf{P}<\mathbf{P} \quad$ Published online June 3, 2020 in advance of the print journal.

Creative This article is distributed under the terms of the

Commons http://creativecommons.org/licenses/by-nc/4.0/, which permits reuse and

License redistribution, except for commercial purposes, provided that the original author and source are credited.

Email Alerting Receive free email alerts when new articles cite this article - sign up in Service the box at the top right corner of the article or click here.

Advance online articles have been peer reviewed and accepted for publication but have not yet appeared in the paper journal (edited, typeset versions may be posted when available prior to final publication). Advance online articles are citable and establish publication priority; they are indexed by PubMed from initial publication. Citations to Advance online articles must include the digital object identifier (DOIs) and date of initial publication.

To subscribe to Cold Spring Harbor Symposia on Quantitative Biology go to: http://symposium.cshlp.org/subscriptions 